\title{
Primary School Teacher's Knowledge towards Attention Deficit/Hyperactivity Disorder (ADHD) and its Associated Factors in Nekemte Town, Oromiya Region, Western Ethiopia
}

\author{
P. Thanasekaran*, Shivaleela P. Upashe and Dereje Chala
}

\author{
Department of Nursing and Midwifery, College of Health and Medical Sciences, Wollega University, \\ P.O. Box: 395, Nekemte, Ethiopia.
}

\begin{tabular}{|c|c|}
\hline Abstract & Article Information \\
\hline 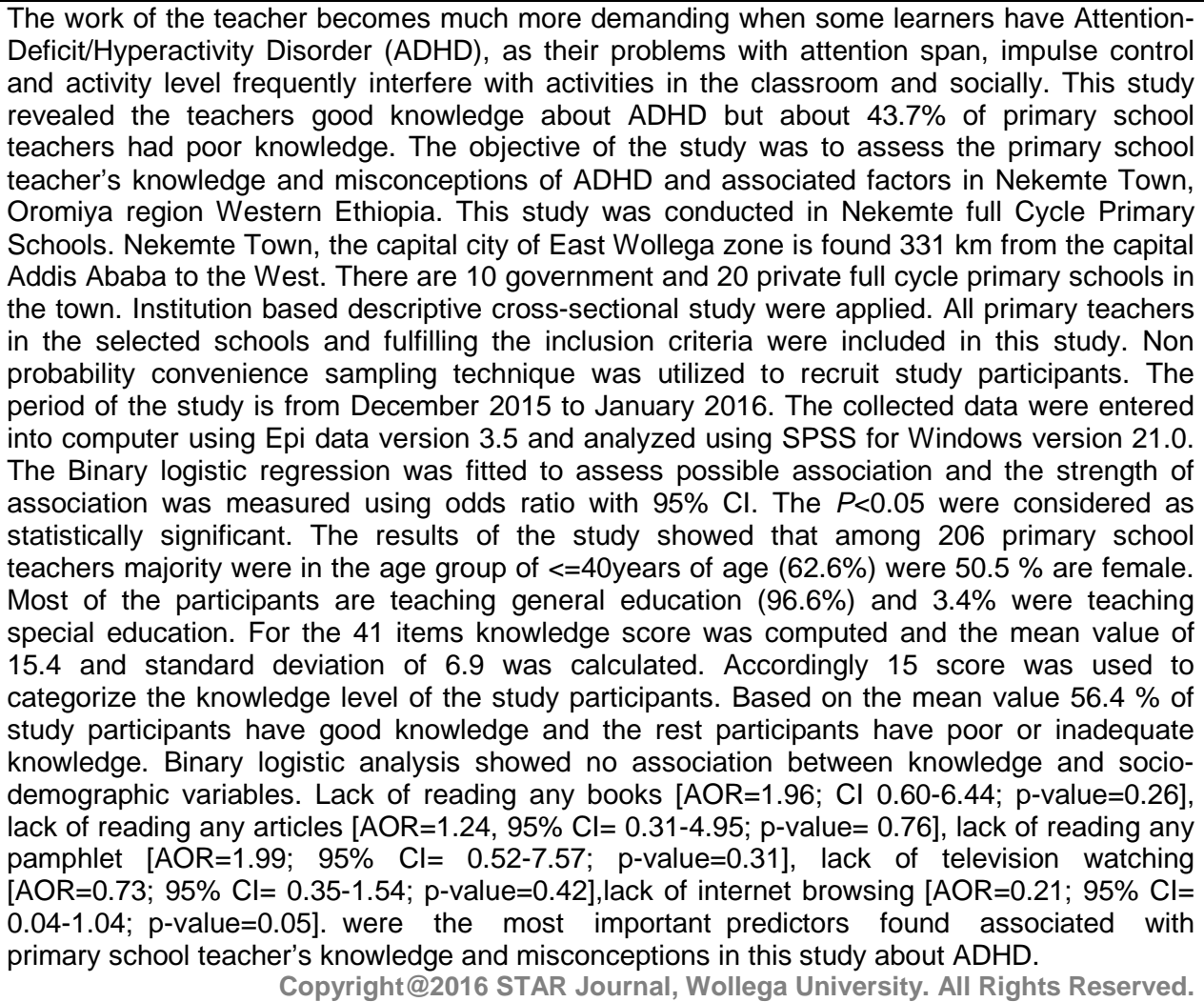 & $\begin{array}{l}\text { Knowledge } \\
\text { primary school teacher } \\
\text { Western Ethiopia } \\
\text { Nekemte } \\
\text { *Corresponding Author: } \\
\text { P. Thanasekaran }\end{array}$ \\
\hline
\end{tabular}

\section{INTRODUCTION}

Knowledge deficit and Hyperactivity Disorder (ADHD) is a diagnostic and statistical tool to analyse the mental health problem that usually diagnosed in children. Children's in school basis are inattentive, impulsive and hyperactive are named as ADHD. Children with ADHD often exhibit social problems including poor peer relations and low self esteem (Barkley, 1998; DuPaul and Stoner, 1994). Common disorder occur about 3\% school age children's. Therefore teachers may have more difficult to teach those students. Teachers play an vital role in the identification and assessment of children's difficulties and have been considered one of the most valuable sources of information with regard to attention deficit hyperactivity disorder (ADHD) diagnoses. About $50 \%$ of students with ADHD do not qualify for special education services and are accommodated full-time in the general education classroom (Reid et al., 1994). A study conducted on teachers and psychological service providers reveals $85 \%$ of respondents reported teaching a child with ADHD, only $39 \%$ had received training in ADHD, and only $16 \%$ of the trained respondents had actually been taught to use a variety of intervention techniques by Gardill, DuPaul, and Kyle, (1996). Most of the Canadian and American samples reported either receiving little or no instruction 
Thanasekaran et al.,

regarding $A D H D$ during their college years, and $89 \%$ of the Canadians and $92 \%$ of the Americans reported receiving little training after graduation. (Liu et al., 1991). A study conducted in Greek suggested that special education teachers are more knowledgeable of issues related to $A D H D$ in comparison to general education teachers. Both general and special educators were found to be most knowledgeable of the definition and characteristics of ADHD and least knowledgeable of its etiology and treatment (Agaia Stampoltzis and Katerina Antonopoulou, 2013). Also in Saudi Arabia teachers reveal overall percentage score of correct responses was $17.2 \%$ which reflect good knowledge of ADHD. The majority of ADHD children evidence some degree of poor school performance in the elementary school years which signify that only less than the third of the teachers knew that most children with ADHD have difficulty with academic performance (Keetam and Alkahtani, 2013). A study done by Airiin Oim the comparison between Estonia and Norway showed, teacher's work experience, quality of teacher's education, having special training, interests and child's gender are the factors associated with knowledge (Õim and Airiin, 2004) . In this study we discussed about primary school teachers knowledge and misconceptions for ADHD children's activities and the factors reasoning the increase in development of mood stabilities and the training.

\section{METHODS AND MATERIALS}

This study was conducted in Nekemte full Cycle Primary Schools. Nekemte town, the capital city of East Wollega zone is found $331 \mathrm{~km}$ from the capital Addis Ababa to the West. There are 10 government and 20 private full cycle primary schools in the town among selected no of Government full cycle primary school 4 and 10 private full cycle primary school. Institution based descriptive cross-sectional study were applied. A total of 206 students were included in the study. All primary teachers in the selected schools and fulfilling the inclusion criteria were included in this study. Non probablity conviniance sampling technique was utilize to recruit study participants. The period of the study is from December 2015 to January 2016.

\section{Inclusion and Exclusion Criteria}

Teachers in the age group of 21 to 65 years of age and teachers those are teaching in the primary school were included in the study. Teachers suffering from or treated for any medical disorder and teachers who attend any training or seminar on ADHD were excluded in the study.

\section{Data Collection Instrument and Procedure}

The data was collected by using Knowledge of Attention Deficit Disorders Scale (KADDS) (Sciutto et al., 2000).

\section{Data Processing and Analysis}

After data collection, each questionnaire was checked for completeness and code had given before data entry.
Sci. Technol. Arts Res. J., Jan-March 2016, 5(1): 76-89

Data was entered and analyzed using SPSS version 20 statistical packages. Different frequency tables, graphs and descriptive summaries were used to describe the study variables. Regression had performed to see the existence of association between dependent and independent variables.

\section{Ethical Consideration}

The proposal was approved by Ethical Review Committee of College of Health and Medical Sciences, Wollega University (Ref No: NMW/75/2008 E.C) and letter of permission was obtained from each school. Verbal and written consents was obtained from the study subjects after explaining the study objectives and procedures and their right to refuse to participate in the study any time they want to. For this purpose, a one-page consent letter was attached to the cover-page of each questionnaire stating about the general purpose of the study and issues of confidentiality which was discussed by data collectors before filling the questionnaire and proceeding with the interview.

\section{RESULTS AND DISCUSSION}

Among 206 primary school teachers majority were in the age group of <=40years of age $(62.6 \%)$ were $50.5 \%$ are female. Most of the participants are teaching general education (96.6\%) and $3.4 \%$ were teaching special education given in Table 1.

Majority (52.4\%) of the primary school teachers learn about ADHD during their teacher training period and after identifying ADHD child, $81.6 \%$ primary school teachers do not spoke to medical professionals regarding control the symptoms. $68.4 \%$ participants have incorrect beliefs regarding $A D H D$ child should deal with full time special education.

For the 41 items knowledge score was computed and the mean value of 15.4 and standard deviation of 6.9 was calculated. Accordingly 15 score was used to categorize the knowledge level of the study participants. Based on the mean value $56.4 \%$ of study participants have good knowledge and the rest participants have poor or inadequate knowledge (Table 2).

\section{Factors Associated with Knowledge towards ADHD}

Teachers asked for the factors that lead to poor knowledge. Binary logistic analysis showed no association between knowledge and socio-demographic variables. But it is claimed that lack of reading books [AOR=1.96; $\mathrm{Cl}$ $0.60-6.44 ; p$-value $=0.26]$, lack of reading any articles [AOR=1.24, 95\% Cl=0.31-4.95; $p$-value $=0.76]$, lack of reading any pamphlet $[\mathrm{AOR}=1.99 ; 95 \% \mathrm{Cl}=0.52-7.57$; $\mathrm{p}$ value $=0.31$ ], lack of television viewing $[A O R=0.73 ; 95 \%$ $\mathrm{Cl}=0.35-1.54 ; \mathrm{p}$-value $=0.42$ ], lack of internet browsing [AOR $=0.21 ; 95 \% \mathrm{Cl}=0.04-1.04 ; p$-value $=0.05]$, were the most important predictors found associated with primary school teacher's knowledge and misconceptions in this study about ADHD. 
Table 1: Socio-demographic characteristics of participants among primary school teachers, Nekemte, Oromia, Western Ethiopia $(n=206)$

\begin{tabular}{lcc}
\hline Demographic variable & Frequency & Percentage \\
\hline Age Group(Yrs) & & \\
$<=40$ & 129 & 62.6 \\
$>41$ & 77 & 37.4 \\
Total & 100 & 100.00 \\
\hline Gender & 102 & \\
Male & 104 & 49.5 \\
Female & 100 & $\mathbf{1 0 0 . 0 0}$ \\
Total & & \\
\hline Highest degree attained & 125 & 60.7 \\
Degree & 81 & 39.3 \\
Diploma & 100 & $\mathbf{1 0 0 . 0 0}$ \\
Total & & \\
\hline Grade levels you currently teach & 103 & 50 \\
$>=5$ & 103 & 50 \\
6-8 & $\mathbf{1 0 0}$ & $\mathbf{1 0 0 . 0 0}$ \\
Total & & \\
\hline Classes you currently teach & 199 & 96.6 \\
General education & 7 & 3.4 \\
Special education & $\mathbf{5 0}$ & $\mathbf{1 0 0 . 0 0}$ \\
Total & & \\
\hline Total number of years of teaching experience & 119 & 57.8 \\
$<=15$ & 87 & 42.2 \\
$>16$ & $\mathbf{2 0 6}$ & $\mathbf{1 0 0}$ \\
Total & & \\
\hline
\end{tabular}

Table 2: Overall mean, standard deviation, knowledge cut-off score, frequency and percentage of primary school teachers on ADHD according to their level of Knowledge, Nekemte, Ethiopia $(n=206)$

\begin{tabular}{ccccccc}
\hline $\begin{array}{c}\text { Knowledge } \\
\text { level }\end{array}$ & Score & \multicolumn{2}{c}{ Primary School Teachers } & $\begin{array}{c}\text { Cut of } \\
\text { Score }\end{array}$ & Mean & $\begin{array}{c}\text { Standard } \\
\text { Deviation }\end{array}$ \\
\cline { 3 - 4 } & & No & $\%$ & & & \\
Good & $15-41$ & 116 & 56.4 & 15 & 15.4 & 6.9 \\
Poor & $0-14$ & 90 & 43.7 & & & \\
\hline
\end{tabular}

Table 3: Association of knowledge with socio demographic variables among primary school teachers, Nekemte, Oromia, Ethiopia $(n=206)$

\begin{tabular}{|c|c|c|c|c|c|c|c|c|c|}
\hline $\begin{array}{l}\text { Experience with } \\
\text { ADHD Variables }\end{array}$ & & $\begin{array}{c}\text { Good } \\
\text { Knowledge }\end{array}$ & $\begin{array}{c}\text { Poor } \\
\text { Knowledge }\end{array}$ & OR & $\begin{array}{c}\text { Confidential } \\
\text { Interval (95\%) }\end{array}$ & $P$-value & AOR & $95 \% \mathrm{Cl}$ & $P$-value \\
\hline \multirow{2}{*}{ In-service } & Yes & $11(64.7)$ & $6(35.3)$ & 1.46 & $0.52-4.13$ & 0.46 & 1.04 & $0.29-3.74$ & 0.94 \\
\hline & No & $105(55.6)$ & $84(4.4)$ & 1 & 1 & 1 & 1 & 1 & 1 \\
\hline \multirow{2}{*}{ Read any books } & yes & $27(71.1)$ & $11(28.9)$ & 2.17 & $1.01-4.67$ & 0.04 & 1.96 & $0.60-6.44$ & 0.26 \\
\hline & No & $89(53)$ & $79(47)$ & 1 & 1 & 1 & 1 & 1 & 1 \\
\hline \multirow{2}{*}{ Read any articles } & Yes & $17(68)$ & $8(32)$ & \multirow{2}{*}{1.73} & \multirow{2}{*}{$0.71-4.23$} & \multirow{2}{*}{0.22} & \multirow{2}{*}{1.24} & \multirow{2}{*}{$0.31-4.95$} & 0.76 \\
\hline & no & $99(55)$ & $81(45)$ & & & & & & 1 \\
\hline \multirow{2}{*}{ Read any pamphlet } & Yes & $20(71.4)$ & $8(28.6)$ & 2.13 & $0.89-5.10$ & 0.08 & 1.99 & $0.52-7.57$ & 0.31 \\
\hline & No & $96(53.9)$ & $82(46.1)$ & 1 & 1 & 1 & 1 & 1 & 1 \\
\hline \multirow{2}{*}{ Watched television } & Yes & $30(56.6)$ & $23(43.4)$ & 1.01 & $0.54-1.90$ & 0.96 & 0.73 & $0.35-1.54$ & 0.42 \\
\hline & No & $86(56.2)$ & $67(43.8)$ & 1 & 1 & 1 & 1 & 1 & 1 \\
\hline \multirow{2}{*}{ Searched the internet } & Yes & $4(40)$ & $6(60)$ & 0.50 & $0.13-1.82$ & 0.29 & 0.21 & $0.04-1.04$ & 0.05 \\
\hline & No & $112(57.1)$ & $84(42.9)$ & 1 & 1 & 1 & 1 & 1 & 1 \\
\hline
\end{tabular}

\section{DISCUSSION}

Only about $74.8 \%$ of teachers had no information about ADHD. About $25.2 \%$ obtained information about ADHD from television (25.7\%), books and magazines $(31 \%)$ and from internet (4.9\%). This is low when compared with study done at Egypt which $31 \%$ of the teachers had no information about ADHD, and most of them gained their knowledge about ADHD from television $(26 \%)$, books and magazines (20\%) and friends and the internet (10\%). This study found that about $56.4 \%$ of study participants have good knowledge. This indicates that teachers have good knowledge when compared with study done in Saudi Arabia which was $17.2 \%$ reflected poor to knowledge of ADHD. When compared with the study done at Canada and America it is less knowledgeable with their understanding of basic concepts about ADHD was good the Canadian sample got $78 \%$ correct and the American sample got $77 \%$ correct. Their knowledge might be attributed to learn about ADHD during their teacher training, since the majority have work experience of less than fifteen years and are also degree 


\section{Thanasekaran et al.,}

holders. Regarding poor knowledge, 43.7\% participants have poor or inadequate knowledge. This reveals near to half instructors lacks of knowledge when compared with study done at Canada and America, and high with study done at Saudi Arabia. This may be due to lack of awareness regarding the disorder (Jerome, Gordon and Hustler, 1994; Woodward, Taylor and Dowdney, 1998).

The study suggests short comings in teacher training practices as well as in the diagnostic and treatment process was psychologists/medical practitioners together with the teachers should be involved. The main value of this study was identifying areas where there is a lack of knowledge among teachers and suggesting ways of providing support and the necessary knowledge in a constructive way. Still $43.7 \%$ of primary school teachers had poor knowledge about ADHD. Factors like do not learn about ADHD during teacher training, lack of inservice presentation, books, articles, pamphlets/handouts on ADHD. Teachers asked for the factors that lead to poor knowledge. Binary logistic analysis showed no association between knowledge and socio-demographic variables. But it is claimed that teacher training, lack of communication between teachers and medical professionals, lack of in service training on ADHD, lack of reading materials like handouts, pamphlets, articles, books, magazines in the school's library. Those factors are in line with the factors stated in Estonia and Norway which were teacher's work experience, quality of teacher's education, having special training, interests and child's genders are the factors associated with knowledge (Piccolo-Torsky, and Waishwell, 1998).

\section{CONCLUSIONS}

This results of the study found that, about $56.4 \%$ of primary school teachers have good knowledge and $43.7 \%$ of had poor knowledge about ADHD. Lack of training about ADHD, lack of in-service presentation, books, articles, pamphlets/handouts on ADHD were the factors that affects knowledge and perception of the teachers. Teachers should be offered in-service training in school, formal education by incorporating in curriculum, and leaflets should regularly disseminated for teachers to increase knowledge by schools.

\section{Acknowledgments}

We would like to acknowledge Wollega University for funding this research project under faculty research grant scheme. Our sincere gratitude also goes to all supervisors, data collectors, and study participants for their cooperation and support during the study period. Lastly, we would like to thank those respective government and non-government schools of Nekemte Town, Western Ethiopia for their cooperation, help, and encouragement during the data collection.

\section{Conflict of Interest}

None declared.

\section{REFERENCES}

Barkley, R.A. (1998). Attention-Deficit Hyperactivity Disorder'. A handbook for diagnosis and treatment (2nd ed.) New York: The Guilford Press.

DuPaul, G.J. and Stoner, G. (1994). ADHD in the schools'. Assessment and intervention strategies. New York: The Guilford Press.
Sci. Technol. Arts Res. J., Jan-March 2016, 5(1): 76-89

Reid, R., Vasa, S., Maag, J. and Wright, G. (1994). An analysis of teachers: perceptions of Attention DeficitHyperactivity Disorder. The Journal of Research and Development in Education 27(3): 195-202.

Gardill, M.C., DuPaul, G.J. and Kyle, K.E. (1996). Classroom strategies for managing students with AttentionDeficit/Hyperactivity Disorder. Intervention in School and Clinic 32(2): 89-94.

Liu, C., Robin, A.L., Brenner, S. and Eastman, J. (1991). 'Social acceptability of methylphenidate and behaviour modification for treatment of attention deficit hyperactivity disorder' Pediatrics 88: 560-565

Agaia Stampoltzis and Katerina Antonopoulou (2013). Knowledge and misconceptions about Attention Deficit Hyperactivity Disorder (ADHD): A comparison of Greek general and special Education teachers' International Journal of School and Educational Psychology 1(2): 122130.

Keetam, D.F., Alkahtani, (2013). Teachers Knowledge and Misconceptions of Attention Deficit/Hyperactivity Disorder, Psychology, scientific research. Psychology 4(12): 963969.

Õim, Airiin (2004). Teacher's knowledge and misconceptions concerning attention deficit/hyperactivity disorder, learning disabilities and childhood depression. Ph.D Thesis: University of Tartu Department of Psychology: 67190.

Jerome, L., Gordon, M. and Hustler, P. (1994). A Comparison of American and Canadian Teachers: Knowledge and Attitudes Towards Attention Deficit Hyperactivity Disorder (ADHD). Canadian Journal of Psychiatry 39: 563-567.

Kuperman, S., Schlosser, S.S., Lindral, J. and Reich, W. (1999). Relationship of child psychopathology to parental alcoholism and antisocial personality disorder' Journal of the American Academy of Child and Adolescent Psychiatry 38(6): 686-692.

Woodward, L., Taylor, E. and Dowdney, L. (1998). The parenting and family functioning of children with hyperactivity. Journal of Child Psychology and Psychiatry 39(2):161-169.

Piccolo-Torsky, J. and Waishwell, L. (1998). Teachers knowledge and attitudes regarding Attention Deficit Disorder. ERS Spectrum 16(1): 36-40.

Whitworth, J. E., Fossler, T. and Harbin, G. (1997). 'Teachers perceptions regarding educational services to students with Attention Deficit Disorder. Rural Educator 19(2): 1-5.

Gardill, M.C., DuPaul, G.J. and Kyle, K.E. (1996). Classroom strategies for managing students with AttentionDeficit/Hyperactivity Disorder. Intervention in School and Clinic 32(2): 89-94.

Stein, M.A., Krasowski, M., Leventhal, B.L., Phillips, W. and Bender, B.G. (1996). Behavioural and cognitive effects of methylxanthines. Archives of Pediatric and Adolescent Medicine 150: 284-288.

Power, T.J., Hess, L.E. and Bennett, D.S. (1995) 'The acceptability of interventions for Attention-Deficit Hyperactivity Disorder among elementary and middle school Teachers. Developmental and Behavioural Pediatrics, 16(4): 238-243.

Reeve, R.E. (1994). The academic impact of ADD. Attention 5(2): 8-12.

Reid, R., Vasa, S., Maag, J. and Wright, G. (1994). An analysis of teachers' perceptions of Attention DeficitHyperactivity Disorder. The Journal of Research and Developmentin Education 27(3): 195-202. 